AREND, Silvia Maria Favero. (Org.) Um país impresso: História do Tempo Presente e revistas semanais no Brasil. Curitiba: CRV, 2014. 232p. ISBN 978-85-444-0071-5.

\title{
Leituras semanais e imagens do presente.
}

Se dedicar à compreensão de parte da história do Brasil durante o século $\mathrm{XX}$ através das fontes impressas, principalmente a partir de sua segunda metade permeado pelos insólitos e tenebrosos acontecimentos políticos e sociais, é uma salutar tarefa ao analisar as densas e numerosas páginas dos escritos periódicos que auxiliaram na difusão de informações e produção de sentidos de boa parte dos núcleos urbanos e das principais cidades do país. Se os jornais impressos circulavam em torno de praças, bancas e pequenos redutos de leitores, durante a década de 1960, as revistas com periodicidade semanal, casos de Veja, Visão e Isto é, passaram a ser ofertadas e postas em circulação nacional. Esta modalidade de publicação periódica, alavancada pelas novas tecnologias midiáticas e gráficas, inaugurou uma modalidade de comunicação de massa capaz de se tornar "em narrativa imediata daqueles anos". Também fora possível perceber o alcance de uma nova dimensão da informação, que assumiram instâncias discursivas capazes de escolher e narrar fatos que deveriam ser memoráveis, feitos e realizações que deveriam ser louvados, bem como pensamentos e ordenamentos sociais que deveriam ser construídos e constituídos nas imagens presentificadas nas páginas impressas em offset.

Ainda, analisar as produções deste país impresso, reflete uma percepção aguçada ao se deparar com a história do tempo presente, sendo que algumas destas revistas ainda circulam nos dias atuais e seus escritos influenciam e contribuem na formação - e por que não formatação? - de opinião de muitos brasileiros e brasileiras.

Silvia Maria de Fávero Arend, docente do Programa de Pós Graduação em História da Universidade do Estado de Santa Catarina - UDESC - organizou a obra que reuniu parte dos resultados atingidos do projeto de pesquisa intitulado "Um país impresso entre culturas políticas e sociabilidades - revistas semanais, projetos sociais e memória histórica no Brasil 1964-1990", projeto este financiado pelo Conselho Nacional de Desenvolvimento Científico e Tecnológico $(\mathrm{CNPq})$. O projeto, que contou com a presença de docentes e discentes da universidade, procurou mediar uma análise que pudesse auxiliar na compreensão histórica dos mercados de publicações impressas no Brasil e como estes mercados possibilitaram alianças 
políticas, a construção imagética e simbólica de um presente em curso, bem como a relação com a cultura e sociabilidades, que tais periódicos inseriram nas temáticas de seus escritos.

Organizado em três partes distintas e alicerçadas sobre nove capítulos, o livro dialoga sobre os usos e formatações do passado pela mídia impressa, desejosa por validar-se como produtora de verdade. Os capítulos permeiam a construção das narrativas, tidas em grande parte das vezes como históricas, construídas pelos jornalistas e editores sobre as matérias várias, que revelam procedimentos de recortes de interesses delimitados, enunciados ímpares e instâncias discursivas que são nesta obra analisados com acuidade e densidade. Também, o livro busca demonstrar como novos atores e temáticas puderam ser inseridos nas publicações periódicas das revistas impressas no Brasil, que, com o transcorrer dos anos e de mutações sociais, encontraram espaços para sua divulgação.

A primeira parte da obra intitulada "Revistas semanais e os usos do passado", traz a discussão de como as revistas puderam se constituir primeiramente como um locus de verdade e de memória, assumindo a posição de uma ferramenta capaz de compreender a realidade passada do país e a projetar mecanismos e ações do futuro, fazendo do presente seu palco de atuação. Os três primeiros capítulos analisam páginas e publicações da revista Veja, aglutinando publicações desde as controvérsias políticas dentre os anos permeados pela ditadura militar aos processos de redemocratização nos idos da década de 1980 .

Os autores discorrem sobre os usos de categorias como memória, tempo, progresso, documento e atos monumentais, que redimensionados e construídos discursivamente, formaram novas significações neste mercado de bens simbólicos, passando a circular com altivez pelas mentes brasileiras. Exposições de longos editoriais e colunas em seções especiais como: "Onde está o inimigo da Pátria", "E ficou a Pátria livre" e "As festas da independência”, revelam que o posicionamento político do periódico estava muito bem delimitado a ser um mecanismo de constituição de uma ordenação simbólica de pensamento, utilizando termos e construção de textos com base em categorias como história, memória, documentos e monumentos, presente e futuro, de modo que palavras-chave como pátria, nação, patriotismo, nacionalismo e revolução - dentre outros - tomaram a cabo como o cerne de formação de novas compreensões e mentalidades do presente.

Os três capítulos iniciais do livro demonstram o intento da revista ao construir uma narrativa tida como histórica, capaz de, ao usar elementos do passado, tornando sessões como documento, memória e história em tentativas de lugares de memória, como lembra Pierre Nora, ao elaborar uma nova significação do presente. Neste sentido, é Paul Ricoeur quem definiu uma correlação entre o ato, a ação ao narrar uma determinada história, ou fato, e 
própria noção de tempo e seu caráter presente nas relações e experiências humanas. Ao passo em que as revistas articulam seus escritos ao constituir uma narrativa tida como histórica, percebe-se de pronto a condição de uma existência temporal, revelando o interesse de se fabricar uma nova constituição de experiência e realidade nas páginas da revista.

Os capítulos seguintes culminam na segunda parte do livro: "Revistas semanais e narrativas históricas", que busca atravessar a década de 1970 até os processos de redemocratização no Brasil durante os primeiros anos da década de 1980. Os capítulos buscam vincular uma análise sobre edições da revista Veja e Isto É, tendo como finalidade compreender as publicações ligadas as temáticas políticas, bem como, perceber como novas pautas se inseriram nas questões propostas pelos periódicos, como a (re)ascenção do movimento estudantil, dos movimentos operários e as novas reinvindicações que começavam a surgir nas principais capitais brasileiras e suas cercanias.

Em uma relação cronológica, a segunda parte do livro fora organizada de modo metodologicamente interessante. O quarto capítulo, primeiro da segunda parte, traça um panorama teórico e o fundamenta a partir de compreensões da história da imprensa e suas influências políticas. $O$ autor constitui uma trama conceitual das relações que a imprensa, a mídia e as ferramentas jornalísticas costuram junto aos cenários político e social, revelando a imprensa e os meios midiáticos de informação, conforme aponta Jurgen Habermas (1984), como um mecanismo importante de agenciamento e gestão de opiniões e mentalidades, atuando em um ordenamento social. O segundo capítulo desta parte, avança entre a segunda metade dos anos 1970 e adentra a década de 1980, analisando como os periódicos constituíram uma interpretação da participação de movimentos contrários ao governo ditatorial, como movimentos estudantis e operários, e, também, novos personagens políticos emergidos destes nichos de oposição, que passavam a constituir como prováveis líderes, tal qual o sindicalista Luís Inacio da Silva. Já o sexto capítulo do livro narra os processos da redemocratização do país e como a ascensão de novas figuras políticas foram centrais para a constituição do cenário da época. As autoras, ao selecionar reportagens e trechos de editoriais e seções da revista, buscaram analisar a constituição de personagens políticos e suas atuações materializadas nas páginas do periódico. Em um contexto político intenso e em transição, o capítulo enfoca na atuação de políticos como Tancredo Neves e João Batista Figueiredo, dois personagens icônicos deste momento da política brasileira. Na avaliação do resenhista, é significativa a utilização de trechos escritos contidos nas capas de algumas edições. Embora as imagens das capas não estejam disponíveis na obra, trechos como "na capa desta edição tínhamos uma foto de Tancredo Neves sorrindo", auxiliam a formação de imagens mentais 
que revelam como a figura do presidente ideal fora sendo construída na mentalidade brasileira, e, como possíveis ferramentas da história do tempo presente foram ali utilizadas com sua potencialidade. Este capítulo demonstra, com uma descrição das fontes e análise contextual das informações, um posicionamento muito maduro quanto ao rigor metodológico e equidade ao deparar a história do tempo presente ao estabelecer análises.

Por fim, a terceira parte do livro, constituído também de três capítulos vai além das temáticas anteriores, complementando o projeto que resultou o livro. Fora reservada a esta última seção o tema: "Revistas semanais e novos atores em cena", e, os capítulos buscaram narrar como as novas conjecturas e cenários contribuíram para que sujeitos e agências surgissem no cenário brasileiro.

O sétimo capítulo analisa as páginas da revista Manchete em suas edições entre os anos de 1975-1985, buscando perceber quais papéis o periódico traria à mulher e quais espaços discussões sobre feminismo e história das mulheres poderiam vir a ser percebidos. A autora destaca a participação de Heloneida Studart, redatora da revista entre os anos de 19701978, em sua atuação em prol das causas feministas e dos direitos das mulheres. Durante seus anos de direção, notou-se uma aguda publicação de matérias, reportagens e entrevistas envolvendo questões ligadas ao feminismo, como maior valorização das mulheres, casamento, "o mal dos homens", textos como "feminismo furioso", indicações de dados estatísticos via autoras feministas como Betty Friedan e reportagens como “75, o ano da Mulher”. Tal circulação revela a potência destas discussões em uma sociedade em emergência e ebulição de novas práticas e paradigmas, servindo como referencial de leitura para muitas mulheres brasileiras. Embora após a saída de Heloneida, a frequência de publicações com estes temas tenham diminuído, a possibilidade de percepção de novas demandas sociais foram inseridas e atualizadas nas pautas dos grandes periódicos.

Nesta perspectiva de emergência de novos sujeitos, o capitulo subsequente relata a ascensão de uma nova classe média. Interessante na construção é perceber como o autor veiculou as informações contidas nas páginas da revista Veja, como propagandas de bens materiais e serviços, serviram para compreender um novo grupo de pessoas em ascensão que passou a vivenciar, experimentar e desejar novas sensibilidades. Partindo de uma análise das representações sociais, da perspectiva do consumo, bem como de uma análise do capital e da história econômica do Brasil dos anos 1970, se constituiu um tecido contextual que permitiu compreender como um novo grupo de pessoas passou a entrar em uma lógica econômica de capital e como os elementos persuasivos da propaganda midiática entraram com força na disputa deste mercado de bens materiais, que também vinculou com um mercado de bens 
também simbólicos, lembrados por Pierre Bourdieu (2013) na construção desta nova classe média.

O capitulo derradeiro da obra, conclui a terceira parte e encerra o livro analisando a figura de atuação de Clara Nunes e sua música popular, redescoberta entre a simbiose ÁfricaBrasil. Nas páginas da revista Veja, propõe-se uma discussão apresentando a vida da cantora, suas principais obras e os ganhos significativos que esta veio a representar para a cultura brasileira e principalmente pelo fato de unir em suas músicas às raízes matricialmente africanas em diálogo com a cultura brasileira. O capítulo traz entrevistas concedidas por Clara Nunes e expõe trechos de suas músicas, revelando a rica e prodigiosa construção musical, artística e cultural proposta pela cantora, que fez-se dar voz a um grupo de pessoas identificadas com as raízes entoadas nos versos de Clara.

Por fim, concordamos que a obra se consolida como uma importante referência para a compreensão da história do tempo presente no Brasil. Se de acordo com Henry Rousso a análise do tempo presente se dá "a partir de uma compreensão sobre uma época que não é simplesmente a compreensão de um passado distante, mas a uma compreensão que vem de uma experiência da qual ele participa como todos os outros indivíduos", chegamos a conclusão que por estabelecer uma análise sólida, como a engendrada pelos diversos autores e organizados por Silvia Maria de Fávero Arend, a obra assume sua importância para a história da mídia, da imprensa e da história política, econômica e cultural do Brasil da segunda metade do século XX. A forma de estruturação do livro revelou uma leitura aprazível, importante para clarear possibilidades analíticas e margear pensamentos vindouros acerca da história do tempo presente e das mídias impressas.

Uma condição em específico poderia ampliar as avaliações positivas da obra, a saber principalmente a utilização de imagens. Em todo o livro, há a construção de imagens imateriais, mentalizadas a partir do universo da leitura ou induzidos como o exemplo citado sobre o sorriso do presidente. Entretanto, mesmo havendo as descrições textuais sobre s riquezas do fotojornalismo e os recursos imagéticos provindos deste, pouco se traz a título de demonstração ou análise. Um capítulo analisando as imagens das capas, as disposições de chamadas ou de imagens e cores, como também a perspectiva critica destas leituras, poderiam vir a somar a deixar a obra ainda mais atraente do que ela já é.

A importância de uma obra como esta é de exponencial valor, e surge em um momento em que muitas pesquisas sobre os anos governados pelos militares no país têm se avolumado, ratificando vez mais sua importância. 